\title{
Effects of Doped Stannum in the Fabrication of Zinc-Oxide Thin-Film Transistors
}

\author{
Hsin-Chiang You ${ }^{1, *}$, Cheng-Yen $\mathrm{Wu}^{2}$, Wen-Luh Yang ${ }^{3}$ \\ ${ }^{1}$ Department of Electronic Engineering, National Chin-Yi University of Technology, Taichung, \\ Taiwan \\ ${ }^{2}$ Ph.D. Program of Electrical and Communications Engineering, Feng Chia University, Taichung, \\ Taiwan \\ ${ }^{3}$ Department of Electronic Engineering, Feng Chia University, Taichung, Taiwan \\ *E-mail: hcyou@ ncut.edu.tw
}

doi: $10.20964 / 10089$

Received: 23 April 2015 / Accepted: 14 March 2016 / Published: 1 April 2016

\begin{abstract}
A sol-gel method was applied with acetates as precursors under standard atmospheric conditions to fabricate $\mathrm{ZnO}$ semiconducting thin-films. We evaluated the performances of thin-film transistor (TFT) which has a $\mathrm{ZnO}$ active channel layer and the effects of stannum (Sn) doping on the threshold voltage of $\mathrm{ZnO}$ TFTs at a low temperature $\left(300{ }^{\circ} \mathrm{C}\right)$, which was compared with the performances of the undoped $\mathrm{ZnO}$ and stannum-doped zinc oxide (ZTO) TFT. The electrical characteristics of thin-films and TFTs doped with stannum concentrations of 0.3 mole ratio were examined; and reductions at the threshold voltage of $5.6 \mathrm{~V}$ were found. At $300{ }^{\circ} \mathrm{C}$, it was observed that the stannum-doped zinc oxide (ZTO) device has a mobility of $4.2 \times 10^{-4} \mathrm{~cm}^{2} / \mathrm{V}$-s, a threshold voltage of $5.3 \mathrm{~V}$, and an on/off current ratio of $10^{4}$.
\end{abstract}

Keywords: Thin-film transistor, threshold voltage, zinc tin oxide, $\mathrm{ZnO}, \mathrm{ZTO}$

\section{$\underline{\text { FULL TEXT }}$}

(C) 2016 The Authors. Published by ESG (www.electrochemsci.org). This article is an open access article distributed under the terms and conditions of the Creative Commons Attribution license (http://creativecommons.org/licenses/by/4.0/). 